\title{
Short- and intermediate-term survival after extracorporeal membrane oxygenation in children with cardiac disease
}

\author{
Constantinos Chrysostomou, MD, ${ }^{\text {a }}$ Victor O. Morell, MD, ${ }^{b}$ Bradley A. Kuch, BS, RRT-NPS, FAARC, ${ }^{a}$ \\ Elizabeth O’Malley, CCP, LP, ${ }^{\mathrm{b}}$ Ricardo Munoz, MD, ${ }^{\mathrm{a}}$ and Peter D. Wearden, $\mathrm{MD}^{\mathrm{b}}$
}

\begin{abstract}
Objectives: In children with cardiac disease, common indications for extracorporeal membrane oxygenation (ECMO) include refractory cardiopulmonary resuscitation (E-CPR), failure to separate from cardiopulmonary bypass (OR-ECMO), and low cardiac output syndrome (LCOS-ECMO). Despite established acceptance, ECMO outcomes are suboptimal with a survival between $38 \%$ and $55 \%$. We evaluated factors associated with significantly increased survival in cardiac patients requiring ECMO.
\end{abstract}

\begin{abstract}
Methods: We conducted a retrospective investigation of consecutive patients undergoing ECMO between 2006 and 2010. Demographic, pre-ECMO, ECMO, and post-ECMO parameters were analyzed. Neurologic outcomes were assessed with the pediatric overall performance category scale at the latest follow-up.
\end{abstract}

Results: There were 3524 admissions, 95 (3\%) of which necessitated ECMO; 40 (42\%) E-CPR, 31 (33\%) ORECMO, and $24(25 \%)$ LCOS-ECMO. The overall hospital survival was $73 \%$. The within-groups hospital survival was $75 \%$ in E-CPR, $77 \%$ OR-ECMO and $62 \%$ LCOS-ECMO. In the multivariable logistic regression analysis, chromosomal anomalies (odds ratio [OR], 8; 95\% confidence interval [CI], 2-35), single ventricle (OR ,6; 95\% CI, 3-33), multiple ECMO runs (OR, 15; 95\% CI, 4-42), higher 24-hour ECMO flows (OR, 8; 95\% CI, 4-22), decreased lung compliance (OR, 5; 95\% CI, 2-16), and need for plasma exchange (OR, 5; 95\% CI, 3-18) were all significant factors associated with mortality. From the univariate analysis, a common parameter associated with mortality within all groups was intracranial hemorrhage. At 1.9 years $(0.9,2.9)$ of follow-up, $66 \%$ were still alive, and $89 \%$ of survivors had normal function or only mild neurodevelopmental disability.

Conclusions: ECMO was successfully used in children with cardiac disease with $73 \%$ and $66 \%$ short- and intermediate-term survival, respectively. The majority of the survivors had normal function or only a minimal neurodevelopmental deficit. (J Thorac Cardiovasc Surg 2013;146:317-25)

Mechanical circulatory support in children with severe cardiac failure is most commonly performed with the use of extracorporeal membrane oxygenation (ECMO). Although other methods of mechanical circulatory support, such as ventricular assist devices (VADs), have emerged in the past decade, in urgent situations and when extracorporeal support is expected to be short-term, ECMO remains the most common method.

In children with cardiac disease, common indications for ECMO include failure to separate from cardiopulmonary bypass (CPB) in the operating room (OR-ECMO), low cardiac output syndrome (LCOS) owing to postoperative myocardial dysfunction, primary myocardial disease, or arrhythmias, in whom continuation or further escalation

\footnotetext{
From the Department of Critical Care Medicine, ${ }^{\text {a }}$ Cardiac Intensive Care Unit, and the Department of Cardiothoracic Surgery, ${ }^{\mathrm{b}}$ Children's Hospital of Pittsburgh of UPMC, Pittsburgh, Pa.

Disclosures: Authors have nothing to disclose with regard to commercial support.

Received for publication May 31, 2012; revisions received Oct 3, 2012; accepted for publication Nov 6, 2012; available ahead of print Dec 10, 2012.

Address for reprints: Constantinos Chrysostomou, MD, Children's Hospital of Pittsburgh of UPMC, 4401 Penn Ave, Pittsburgh, PA 15224 (E-mail: chrycx@ chp.edu). $0022-5223 / \$ 36.00$

Copyright (c) 2013 by The American Association for Thoracic Surgery http://dx.doi.org/10.1016/j.jtcvs.2012.11.014
}

of therapy outweighs the potential risks of ECMO (LCOS-ECMO), and cardiopulmonary resuscitation (CPR) that is refractory to conventional resuscitation measures (E-CPR). LCOS was defined as signs and symptoms of significant low cardiac output (eg, oliguria or anuria, tachycardia, hypotension, prolonged capillary refill) and metabolic acidosis, with or without wide arteriovenous oxygen difference, that either worsen or do not improve despite increased pharmacologic intervention.

Despite established acceptance, outcomes among institutions vary and overall survival has remained between $38 \%$ and $55 \%$, even among centers with longstanding experience. $^{1-7}$

In this large institutional study, we describe the Children's Hospital of Pittsburgh approach to the management of cardiac patients requiring E-CPR, OR-ECMO, and LCOSECMO. We analyze factors affecting morbidity and survival including cardiac anatomy and physiology, cardiac surgery, method of ECMO deployment and decannulation, and other support variables. In addition, we describe our immediate and intermediate-term neurologic outcomes.

\section{METHODS}

The study was performed in the cardiac intensive care unit of Children's Hospital of Pittsburgh, a tertiary academic center with an active heart-lung 


\begin{tabular}{|c|c|}
\hline \multicolumn{2}{|c|}{ Abbreviations and Acronyms } \\
\hline ACT & $=$ activated clotting time \\
\hline APTT & $\begin{array}{l}=\text { activated partial thromboplastin } \\
\text { time }\end{array}$ \\
\hline CI & $=$ confidence interval \\
\hline $\mathrm{CPB}$ & $=$ cardiopulmonary bypass \\
\hline CPR & $=$ cardiopulmonary resuscitation \\
\hline ECMO & $\begin{aligned}= & \text { extracorporeal membrane } \\
& \text { oxygenation }\end{aligned}$ \\
\hline E-CPR & $\begin{aligned}= & \text { refractory cardiopulmonary } \\
& \text { resuscitation }\end{aligned}$ \\
\hline LCOS & $=$ low cardiac output syndrome \\
\hline OR & $=$ odds ratio \\
\hline OR-EC & $\begin{aligned}= & \text { failure to separate from } \\
& \text { cardiopulmonary bypass in the } \\
& \text { operating room }\end{aligned}$ \\
\hline POPC & $\begin{aligned}= & \text { Pediatric Overall Performance } \\
& \text { Category }\end{aligned}$ \\
\hline VAD & $=$ ventricular assist device \\
\hline
\end{tabular}

transplantation and mechanical circulatory support program. Approval from the institutional review board was obtained to retrospectively review our ECMO database and associated medical records for a 5-year period between January 2006 and December 2010.

\section{ECMO and E-CPR Program at Children's Hospital of Pittsburgh}

During the study period between 2006 and 2010 the structure of the cardiac ECMO team remained the same and consisted of 2 cardiothoracic surgeons, 3 cardiac intensivists, and 10 ECMO specialists.

All patients are supported with venoarterial ECMO, and the cannulation site is either peripheral (neck or femoral vessels) or chest (right atrium and aorta) depending on the surgical status of the patient. The ECMO circuit involves a roller pump (Stockert-Shiley SIII, Sorin Group, Arvada, Colo), with either $1 / 4$-inch or 3/8-inch diameter tubing, and an appropriate-sized oxygenator. Circuit size is based on patient weight with patients weighing more than $11.0 \mathrm{~kg}$ being supported by $3 / 8$-inch circuits and those weighing less than $11 \mathrm{~kg}$ on the $1 / 4$-inch version. Until mid-2009, both size circuits consisted of Carmeda-coated tubing and a hollow-fiber oxygenator (Minimax or Affinity; Medtronic, Inc, Minneapolis, Minn). Subsequently, our program converted from the hollow-fiber oxygenators to Bioline-coated Quadrox iD (for $<11 \mathrm{~kg}$ ) and Poly-methyl-Pentene Quadrox D oxygenators (for $>11 \mathrm{~kg}$ ) (Maquet, Wayne, NJ). At all times there was one circuit of each size of tubing primed with crystalloid solution (Plasma-Lyte A; Baxter Healthcare Corporation, Deerfield, Ill) in the cardiac intensive care unit.

Patients whose ECMO support is initiated in the cardiac intensive care unit are administered a loading dose of heparin (30-50 U/kg depending on their coagulation status) 3 to 5 minutes before cannulation. The initial pump flow target is 120 to $160 \mathrm{~mL} \cdot \mathrm{kg}^{-1} \cdot \mathrm{min}^{-1}$ and subsequently adjusted to each patient's requirements to maintain end-organ perfusion, normalization of blood gases, clearance of lactic acidosis, and adequate emptying of the failed ventricle. In general, patients with a patent Blalock-Taussig shunt have their shunt partially clipped. Within the first hour after cannulation, and once ECMO flow goals are met, inotropic agents are discontinued, ventilatory settings are changed to "ECMO resting ventilatory settings" including a positive end-expiratory pressure of 8 to $10 \mathrm{~cm} \mathrm{H}_{2} \mathrm{O}$, inspired oxygen fraction of 0.3 , tidal volume of 4 to $5 \mathrm{~mL} / \mathrm{kg}$, peak inspiratory pressure of $25 \mathrm{~cm} \mathrm{H}_{2} \mathrm{O}$ or less, and ventilation rate of 10 to 14 breaths $/ \mathrm{min}$. Temperature is maintained between $36^{\circ} \mathrm{C}$ and $37^{\circ} \mathrm{C}$ for noncardiac arrest patients and $34^{\circ} \mathrm{C}$ and $36^{\circ} \mathrm{C}$ after cardiac arrest for 24 hours. Cannula position is confirmed by chest radiograph and echocardiography. Sedatives and analgesics are started only after patients have shown satisfactory neurologic status and include dexmedetomidine and fentanyl to maintain comfort and maintain a mild to moderate level of sedation. Movement is generally allowed so long as there is no significant bleeding and it does not interfere with ECMO mechanics. When muscle relaxation is needed, the drug of choice is cisatracurium. Broad-spectrum antibiotics with cefipime are started. Diuretics are given to achieve negative fluid balance and, when not sufficient, slow intermittent ultrafiltration is used. For the ultrafiltration, a hemofilter is placed in series with the ECMO circuit and plasma water is removed as needed and as tolerated to achieve an approximate 5 to $10 \mathrm{~mL}$ negative fluid balance per hour.

Subsequent monitoring includes arterial blood gases and electrolytes every hour until stable and then every 2 to 4 hours, hemoglobin, platelets, and lactic acid level every 4 to 6 hours, creatinine level every 12 hours, chest radiograph 1 to 2 times daily, blood cultures and head ultrasound daily, and an initial electroencephalogram.

After the initial heparin loading, further anticoagulation is achieved with continuous infusion of unfractionated heparin administered via the venous limb of the circuit and is started 12 to 18 hours after cannulation. Coagulation status is evaluated using a multifactorial approach with both point-of-care and conventional laboratory testing. All point-of-care measurements were obtained using the Hemacron Jr. Signature Elite (International Technidyne Corporation, Edison, NJ), which includes activated clotting time (ACT) and whole blood activated partial thromboplastin time (APTT) every 1 hour. Conventional laboratory testing with plasma APTT, prothrombin time, international normalized ratio, and fibrinogen is monitored every 4 hours. Antithrombin III level, antifactor Xa for unfractionated heparin, and thromboelastogram with and without heparinase are obtained every 12 to 24 hours. The general target guidelines for anticoagulation include an ACT of 170 to 200 seconds, an APTT of 70 to $100 \mathrm{sec}-$ onds, antifactor Xa of 0.35 to $0.65 \mu \mathrm{g} / \mathrm{mL}$, international normalized ratio less than 2, and fibrinogen greater than 150 . Hematocrit is usually kept greater than 30 and platelets greater than $100,000 / \mathrm{cm}^{3}$. Heparin dosing adjustment is based on the results of ACT, antifactor Xa level, APTT, and thromboelastogram and taking into consideration clinical judgment.

One of the most important steps in this process is the assessment of readiness for decannulation. This starts almost immediately after cannulation and subsequently is performed at a minimum of twice daily. The cardiac evaluation includes an echocardiogram to assess ventricular function, rule out any left ventricular and atrial distention, valvular insufficiency, and pericardial effusion and to evaluate for any residual defects in patients who had undergone cardiac surgery. Pulmonary assessment includes measurement of pulmonary compliance, and patients with significantly decreased compliance routinely receive exogenous surfactant. If left-sided structures are distended and associated with pulmonary edema, a lowdose epinephrine infusion is started to improve contractility. If no benefit is noted, then a left atrial or ventricular vent is inserted or a balloon atrial septostomy is performed in the cardiac catheterization laboratory. These interventions are performed the same day and before pulmonary edema worsens or pulmonary hemorrhage develops. The echocardiograms are performed mostly by the cardiac intensivists and are usually very brief ( $<1-2$ minutes) and performed with minimal ECMO flows $(20-30 \mathrm{~mL} /$ $\mathrm{kg}$ ) while hemodynamic parameters are observed for any deterioration. If no significant deterioration is noted, that is, low systemic blood pressure and or high filling pressures, and ventricular function and pulmonary compliance appear adequate, including arterial pulsatility, a bridge is placed between the arterial and venous cannulas and the patient is isolated from the ECMO circuit. At the same time mechanical ventilation is optimized for spontaneous circulation, a low-dose infusion of epinephrine 
at $0.05 \mu \mathrm{g} \cdot \mathrm{kg}^{-1} \cdot \mathrm{min}^{-1}$ and milrinone at $0.5 \mu \mathrm{g} \cdot \mathrm{kg}^{-1} \cdot \min ^{-1}$ are started and the patient is decannulated within 1 hour if no hemodynamic decline or significant metabolic acidosis occurs.

If several attempts to wean from ECMO are unsuccessful and no further early cardiac recovery is anticipated, evaluation is started to convert from ECMO to a VAD and subsequently to heart transplantation if needed. Although during the initial study period some patients were converted directly from ECMO to heart transplantation, in general we no longer practice this approach. This decision was based on our encouraging results with the use of VADs and the rather inferior results with the former approach. Transition from ECMO to VAD serves as a bridge to heart transplantation or to myocardial recovery and therefore in general patients who have an absolute contraindication to heart transplantation are not candidates for a VAD either.

\section{Data Collection and Categorization}

Data collected included demographic information, chromosomal and major noncardiac structural abnormalities, cardiac diagnosis and surgery, Aristotle complexity score, need for reoperation, CPR and ECMO parameters, ventilatory support, surrogates of cardiac function and cardiac output, inotropic support, bloodstream infections, complications, and long-term neurologic outcomes. ${ }^{8}$ The primary outcome variable was survival to discharge from the hospital to either home or another facility.

Patients were divided into 3 major categories: E-CPR, OR-ECMO, and LCOS-ECMO. Subsequently and because of the diversity of cardiac lesions and physiology, patients were grouped into the following subgroups: (1) single-ventricle lesions (patients with 1 functional ventricle); (2) 2-ventricle lesions; (3) primary myocardial disease (including patients with heart transplantation); and (4) primary pulmonary hypertension.

Complications during ECMO were categorized as follows: (1) brain injury (clinical or electroencephalographic seizures, significant central nervous system hemorrhage including epidural or subdural hematoma, subarachnoid hemorrhage and greater than grade I intraventricular hemorrhage, and infarction or diffuse ischemic changes based on ultrasound or computed tomographic scan); (2) renal injury (serum creatinine $\geq 1.5$ $\mathrm{mg} / \mathrm{dL}$ or dialysis use via hemodialysis, continuous venovenous hemodialysis or hemofiltration); (3) bloodstream bacterial infection; (4) respiratory complications (ventilator-associated pneumonia, acute respiratory distress syndrome, pulmonary hemorrhage, or pneumothorax); (5) cardiac complications (new arrhythmias that required treatment, CPR, and inotropic support); (6) gastrointestinal complications (gastrointestinal hemorrhage or hyperbilirubinemia [defined as serum-conjugated bilirubin $\geq 2 \mathrm{mg} / \mathrm{dL}$ or total bilirubin $\geq 15 \mathrm{mg} / \mathrm{dL}$ ); (7) bleeding (cannulation or surgical site bleeding, hemothorax, and hemopericardium requiring intervention); (8) mechanical circuit complications (air emboli, thrombus formation in the circuit, breaks or leaks developing in any part requiring circuit change, and oxygenator failure).

Ventricular function was graded on the basis of available echocardiograms within 24 hours before and after ECMO decannulation. Function was graded as normal $=1$, mildly depressed $=2$, moderately depressed $=3$, and severely depressed $=4$.

The cardiac E-CPR team consists of an attending cardiac surgeon and fellow, an attending cardiac intensivist and fellow, a perfusionist, and nursing staff. The decision to activate the cardiac E-CPR team is made by the bedside cardiac intensive care unit physician, and it is usually initiated if there is failure of return of spontaneous circulation after 1 round of resuscitation drugs. However, owing to time logistics related to the preparation for ECMO, cannulation does not occur until after 3 rounds of resuscitation drugs are given. If spontaneous circulation is witnessed beforehand, then cannulation is aborted. Resuscitation drugs routinely include epinephrine, sodium bicarbonate, and calcium chloride every 3 minutes. Chest compression quality is vigorously monitored via the arterial line or the telemetry electrocardiographic tracing if a reliable arterial line is not available. The surface electrocardiographic amplitude is used as a surrogate of chest compression depth, and the person performing chest compressions is under sterile attire to avoid any significant interruption during ECMO cannulation.

CPR data included first documented rhythm before CPR, first pulseless rhythm, duration of $\mathrm{CPR}$, intubation status before CPR, resuscitation drugs, and worst $\mathrm{pH}$ and lactate levels within 6 hours before CPR.

ECMO flows and temperature were assessed at 4 and 24 hours after cannulation. Worst lactic acid level and $\mathrm{pH}$ were recorded within 6 hours before and after cannulation. Peak creatinine and bilirubin levels were recorded during ECMO. Inotropic support after ECMO was defined on the basis of the need for epinephrine during the first hour after decannulation.

Patent ductus arteriosus ligation, left atrial vent, balloon atrial septostomy, and any major noncardiac operations during ECMO were considered invasive interventions and not cardiac reoperations.

To assess global neurologic status, we used the Pediatric Overall Performance Category (POPC) scale. ${ }^{9}$ This score was assigned to survivors at time of the latest outpatient follow-up if adequate neurodevelopmental information was available in medical records.

\section{Definitions}

ECMO recovery: presence of "native" circulation for 48 hours after decannulation. ECMO recannulation: second ECMO run within 48 hours of decannulation. Multiple ECMO runs: 2 or more runs during hospitalization. Twenty-eight-day survival: alive at 28 days after initiation of ECMO. ECMO survival: alive at time of hospital discharge or transfer to another facility; Cardiac surgery: cardiac surgery that occurred during the same admission as ECMO use.

\section{Statistical Analysis}

If a patient had multiple ECMO runs, only the first ECMO run was included in the analysis. Demographics, pre-ECMO, ECMO, and postECMO factors and complications were compared between survivors and nonsurvivors for each major ECMO category separately. Data are presented as frequency (n) with proportion (percent) and median with interquartile range. Categorical data were compared with Fisher's exact test or the $\chi^{2}$ test where appropriate and continuous data with the Wilcoxon test for 2-group comparison or Kruskal-Wallis test for 3-group comparison.

Two separate multivariable logistic regression models were developed to identify factors independently associated with mortality. The logistic regression analysis included all ECMO patients, and the ECMO subgroups served as independent variables. The first model investigated the influence of baseline demographic and pre-ECMO factors whereas the second model analyzed the association of variables during ECMO support including complications. Variables entered the multivariate model only if their probability value from the univariate analysis was 0.1 or less. Variables containing continuous data were retained in the model only if assumption of linearity was met. Variables not meeting the linearity assumption were divided into categories and included in the model as categorical variables. Depending on the variable, values were then dichotomized to either below or above the 25 th or 75 th percentile among patients who died. Each model was assessed for fitness against actual outcomes with the Hosmer-Lemeshow goodnessof-fit test. A $P$ value $>.05$ suggested that the model was fit to the data well. Additionally, a correlation matrix was performed to evaluate for multicollinearity, and variables with statistically significant medium or strong correlation were excluded from the multivariate model. Analysis was performed with JMP version 9.0 (SAS Institute, Inc, Cary, NC).

\section{RESULTS}

\section{Study Population}

During the study period from January 2006 to December 2010 , there were a total of 3524 admissions to the cardiac intensive care unit, $95(2.7 \%)$ of which required 103 
ECMO runs. Tables 1 to 3 demonstrate the demographic information of these patients. There were $40(42 \%)$ patients in the E-CPR group, $31(33 \%)$ in the OR-ECMO, and 24 $(25 \%)$ in the LCOS-ECMO. The overall survival to hospital discharge was $73 \%$ and at the time of study completion, at a median time of 1.9 years $(0.9,2.9)$ from discharge, 63 patients $(66 \%)$ were still alive.

\section{Pre-ECMO and ECMO Factors}

Tables 2 to 4 show a comparison of the pre-ECMO and ECMO support variables between survivors and nonsurvivors.

E-CPR group. All E-CPR patients were receiving chest compressions at the time of ECMO cannulation. More nonsurvivors required pre-ECMO high-frequency oscillatory ventilation and nitric oxide and a higher epinephrine dose. Additionally, nonsurvivors had a lower $\mathrm{pH}$ and a higher lactate level (Table 2). The 3 nonsurvivors with chromosomal defects all had significant abnormalities including methyltetrahydrofolate reductase deficiency and development of multiple systemic thromboemboli, trisomy 21 with significant midfacial hypoplasia and B-cell immunodeficiency, and futile mitochondrial DNA mutation.

OR-ECMO group. Nonsurvivors had higher ECMO flows at 4 and 24 hours, had longer ECMO duration, and after decannulation they had worse ventricular function and required a higher epinephrine dose (Table 3).

LCOS-ECMO group. No difference was noted in the preECMO variables. During ECMO, nonsurvivors had higher ECMO flows at 24 hours, more nonsurvivors had a lactate level of more than 5, and there was a trend toward more nonsurvivors receiving plasma exchange (Table 4). Additionally, the LCOS-ECMO group had significantly longer ECMO duration (87 hours $[59,191])$ than the E-CPR group (50 hours $[29,97][P=.02])$ than the OR-ECMO group (38 hours $[24,84][P=.007])$.

\section{ECMO Complications}

Table 5 illustrates the complications between survivors and nonsurvivors.

E-CPR. Overall, nonsurvivors had significantly more complications than survivors. Among the complications, intracranial hemorrhage had the highest incidence.

OR-ECMO. All 7 nonsurvivors had at least 1 complication each. None of the survivors had intracranial hemorrhage.

LCOS-ECMO. All nonsurvivors had at least 1 complication each. Intracranial hemorrhage was seen in $33 \%$ of nonsurvivors versus $0 \%$ in survivors $(P=.005)$. Furthermore, more nonsurvivors experienced oxygenator failure (Table 5).

Overall, among all study patients, $56 \%$ had at least 1 complication. Neurologic injury was detected in 21 $(22 \%)$ patients, with intracranial hemorrhage in $11(12 \%)$ and cerebral infarct in $6(6 \%)$. Significant residual cardiac defects needing surgical repair were observed in only 2 of the $62(3 \%)$ surgical cases.

\section{Multivariable Logistic Regression Analysis of Factors Associated With Mortality}

The results of the multivariable logistic regression models are shown in Table 6. Corrected gestational age, ECMO flows at 4 hours, worst $\mathrm{pH}$, and lactate in the first

TABLE 1. Demographic features of all ECMO patients

\begin{tabular}{|c|c|c|c|c|c|c|c|c|c|}
\hline & \multicolumn{3}{|c|}{ E-CPR } & \multicolumn{3}{|c|}{ OR-ECMO } & \multicolumn{3}{|c|}{ LCOS-ECMO } \\
\hline & $\mathbf{S}$ & NS & $P$ & $\mathbf{S}$ & NS & $\boldsymbol{P}$ & $\mathbf{S}$ & NS & $P$ \\
\hline $\mathrm{N}(\%)$ & $30(75.0)$ & $10(25.0)$ & & $24(77.0)$ & $7(23.0)$ & & $15(62.5)$ & $9(37.5)$ & \\
\hline Age, d & $84(19,870)$ & $13(7,150)$ & .03 & $10(6,176)$ & $22(5,36)$ & .68 & $16(5,5 y)$ & $140(2,912)$ & .76 \\
\hline Weight, kg & $4.9(3.4,9.9)$ & $2.9(2.5,5.0)$ & .01 & $3.6(3.0,5.0)$ & $2.5(2.0,3.0)$ & .01 & $3.4(3.2,16.1)$ & $3.8(3.0,15.2)$ & .90 \\
\hline Gestational age, wk & $42(40,48)$ & $40(38,42)$ & .08 & $38(36,39)$ & $36(33,40)$ & .18 & $38(37,41)$ & $37(34,39)$ & .10 \\
\hline Sex, M (\%) & $17(57)$ & $8(80)$ & .17 & $14(58)$ & $4(57)$ & 1.00 & $9(60)$ & $5(56)$ & .83 \\
\hline Cardiac diagnosis & & & .005 & & & .64 & & & .25 \\
\hline SV, n (\%) & $4(13)$ & $7(70)$ & .001 & $7(29)$ & $3(43)$ & & $2(13)$ & $3(33)$ & \\
\hline $2-\mathrm{V}, \mathrm{n}(\%)$ & $16(53)$ & $1(10)$ & .04 & $16(67)$ & $4(57)$ & & $6(40)$ & $5(56)$ & \\
\hline PMD, n (\%) & $8(27)$ & $2(20)$ & & $1(4)$ & 0 & & $6(40)$ & $1(11)$ & \\
\hline PPHTN, n (\%) & $2(7)$ & & & & & & $1(7)$ & 0 & \\
\hline Cardiac surgery n $(\%)$ & $14(47)$ & $4(40)$ & 1.00 & $24(100)$ & $7(100)$ & 1.00 & $6(40)$ & $7(78)$ & .10 \\
\hline Aristotle level, n (\%) & & & .11 & & & .67 & & & .88 \\
\hline 1 & $1(7)$ & 0 & & $2(8)$ & 0 & & 0 & 0 & \\
\hline 2 & $3(21)$ & 0 & & $4(17)$ & $2(29)$ & & $1(17)$ & 0 & \\
\hline 3 & $3(21)$ & 0 & & $4(17)$ & $2(29)$ & & $2(33)$ & $3(43)$ & \\
\hline 4 & $7(50)$ & $4(100)$ & & $14(58)$ & $3(43)$ & & $3(50)$ & $4(57)$ & \\
\hline Chromosomal anomalies, $\mathrm{n}(\%)$ & $3(10)$ & $3(30)$ & 0.15 & $4(17)$ & $2(29)$ & .59 & 0 & $5(56)$ & .002 \\
\hline
\end{tabular}

$E C M O$, Extracorporeal membrane oxygenation; $E-C P R$, refractory cardiopulmonary resuscitation; $O R-E C M O$, failure to separate from cardiopulmonary bypass in the operating room; $L C O S$, low cardiac output syndrome; $S$, survivors; $N S$, nonsurvivors; $S V$, single ventricle; 2-V, two ventricles; $P M D$, primary myocardial disease; $P P H T N$, primary pulmonary hypertension. 
TABLE 2. Pre-ECMO and ECMO variables in the 40 E-CPR patients

\begin{tabular}{|c|c|c|c|}
\hline & $\begin{array}{c}\text { Survivors } \\
(\mathbf{n}=\mathbf{3 0})\end{array}$ & $\begin{array}{c}\text { Nonsurvivors } \\
\quad(\mathbf{n}=\mathbf{1 0})\end{array}$ & $\boldsymbol{P}$ \\
\hline \multicolumn{4}{|l|}{ Pre-ECMO } \\
\hline Pre-ECMO/pre-CPR VF & $3(2,4)$ & $4(3,4)$ & .30 \\
\hline Pre-ECMO therapies & & & .12 \\
\hline Nitric oxide, n (\%) & $8(27)$ & $5(50)$ & .24 \\
\hline HFOV, n (\%) & 0 & $1(10)$ & .25 \\
\hline CPR duration, min & $40(25,50)$ & $37(35,50)$ & .84 \\
\hline \multicolumn{4}{|l|}{ Categorized ABG pH } \\
\hline $\mathrm{pH}$ & $7.35(7.03,7.43)$ & $7.23(7.11,7.49)$ & .95 \\
\hline $\mathrm{pH}<7.21, \mathrm{n}(\%)$ & $10(33)$ & $4(40)$ & .71 \\
\hline Lactate, $\mathrm{mmol} / \mathrm{L}$ & $5(3,15)$ & $12(3,19)$ & .32 \\
\hline Lactate $>5, \mathrm{n}(\%)$ & $13(46)$ & $6(67)$ & .47 \\
\hline $\begin{array}{l}\text { Epinephrine, } \\
\quad \mu \mathrm{g} \cdot \mathrm{kg}^{-1} \cdot \min ^{-1}\end{array}$ & $0.09(0.01,0.18)$ & $0.2(0.07,1.0)$ & .05 \\
\hline \multicolumn{4}{|l|}{ ECMO } \\
\hline Cannulation site & & & .72 \\
\hline Chest, n (\%) & $15(50)$ & $4(40)$ & \\
\hline Neck, n (\%) & $15(50)$ & $6(60)$ & \\
\hline $\begin{array}{l}\text { ECMO flow at } 4 \mathrm{~h}, \\
\mathrm{~mL} \cdot \mathrm{kg}^{-1} \cdot \mathrm{min}^{-1}\end{array}$ & $132(100,156)$ & $148(105,185)$ & .28 \\
\hline $\begin{array}{l}\text { ECMO flow at } 24 \mathrm{~h}, \\
\mathrm{~mL} \cdot \mathrm{kg}^{-1} \cdot \mathrm{min}^{-1}\end{array}$ & $129(104,143)$ & $135(115,164)$ & .43 \\
\hline \multicolumn{4}{|l|}{ Categorized ABG pH } \\
\hline $\mathrm{pH}$ & $7.5(7.35,7.55)$ & $7.3(7.18,7.33)$ & .001 \\
\hline $\mathrm{pH}<7.21, \mathrm{n}(\%)$ & 0 & $3(30)$ & .01 \\
\hline Lactate, $\mathrm{mmol} / \mathrm{L}$ & $3(2,5)$ & $13(7,23)$ & $<.001$ \\
\hline Lactate $>5, \mathrm{n}(\%)$ & $5(17)$ & $7(78)$ & .003 \\
\hline Temperature at $4 \mathrm{~h}$ & $34.8(34.0,35.4)$ & $35.5(34.6,36.1)$ & .15 \\
\hline Temperature at $24 \mathrm{~h}$ & $35.6(34.7,36.3)$ & $35.6(34.0,36.6)$ & 1.00 \\
\hline \multicolumn{4}{|l|}{ Ventilatory support } \\
\hline Rate, breaths/min & $15(10,16)$ & $11(10,18)$ & .56 \\
\hline PIP, $\mathrm{cm} \mathrm{H}_{2} \mathrm{O}$ & $24(22,28)$ & $26(20,32)$ & .51 \\
\hline PEEP, $\mathrm{cm} \mathrm{H}_{2} \mathrm{O}$ & $8(6,10)$ & $9(5,10)$ & .93 \\
\hline Tidal volume, $\mathrm{mL} / \mathrm{kg}$ & $7(4,8)$ & $7(3,10)$ & .80 \\
\hline $\begin{array}{l}\text { Compliance, } \\
\qquad \mathrm{mL} \cdot \mathrm{kg}^{-1} \cdot \mathrm{cm} \mathrm{H}_{2} \mathrm{O}^{-1}\end{array}$ & $0.4(0.3,0.5)$ & $0.3(0.2,0.6)$ & .58 \\
\hline Fluid balance, $\mathrm{mL} / \mathrm{kg}$ & $-16(-76,94)$ & $20(-220,133)$ & .82 \\
\hline Plasma exchange, $\mathrm{n}(\%)$ & $4(13)$ & $3(30)$ & .33 \\
\hline ECMO duration, $\mathrm{h}$ & $53(29,98)$ & $48(28,102)$ & .96 \\
\hline Post-ECMO VF & $2(1,3)$ & $3(2,4)$ & .09 \\
\hline $\begin{array}{l}\text { Post-ECMO epinephrine, } \\
\qquad \mu \mathrm{g} \cdot \mathrm{kg}^{-1} \cdot \mathrm{min}^{-1}\end{array}$ & $0.07(0.05,0.19)$ & $0.1(0.08,1.00)$ & .19 \\
\hline $\begin{array}{l}\text { Redo cardiac surgery, } \\
\mathrm{n}(\%)^{*}\end{array}$ & $1(7) \dagger$ & 0 & 1.00 \\
\hline $\begin{array}{l}\text { Invasive interventions, } \\
\mathrm{n}(\%)\end{array}$ & $3(10)$ & $1(10)$ & 1.00 \\
\hline
\end{tabular}

$\overline{E C M O}$, Extracorporeal membrane oxygenation; $E-C P R$, refractory cardiopulmonary resuscitation; $C P R$, cardiopulmonary resuscitation; $V F$, ventricular function; $H F O V$, high-frequency oscillatory ventilation; $A B G$, arterial blood gas; $P I P$, peak inspiratory pressure; $P E E P$, positive end-expiratory pressure. *Percent among patients who had cardiac surgery. †Enlargement of fenestrated ventricular septal defect.

6 hours of ECMO were excluded from the analysis owing to multicollinearity with weight, ECMO flows at 24 hours, $\mathrm{pH}$ less than 7.21, and lactate greater than 5, respectively. Model 1 revealed that having single ventricle, chromosomal/structural abnormalities, and multiple ECMO runs increased the likelihood of mortality significantly. In model
TABLE 3. Pre-ECMO and ECMO variables in the 31 OR-ECMO patients

\begin{tabular}{|c|c|c|c|}
\hline & $\begin{array}{c}\text { Survivors } \\
(\mathbf{n}=\mathbf{2 4})\end{array}$ & $\begin{array}{c}\text { Nonsurvivors } \\
(\mathbf{n}=7)\end{array}$ & $P$ \\
\hline \multicolumn{4}{|l|}{ Pre-ECMO } \\
\hline Pre-ECMO VF & $2(1,3)$ & $3(1,3)$ & .82 \\
\hline \multicolumn{4}{|l|}{ Pre-ECMO therapies } \\
\hline Nitric oxide, n (\%) & $7(30)$ & $4(57)$ & .16 \\
\hline \multicolumn{4}{|l|}{ ECMO } \\
\hline $\begin{array}{l}\text { ECMO flow at } 4 \mathrm{~h}, \\
\mathrm{~mL} \cdot \mathrm{kg}^{-1} \cdot \mathrm{min}^{-1}\end{array}$ & $142(110,152)$ & $205(140,317)$ & .03 \\
\hline $\begin{array}{l}\text { ECMO flow at } 24 \mathrm{~h}, \\
\mathrm{~mL} \cdot \mathrm{kg}^{-1} \cdot \mathrm{min}^{-1}\end{array}$ & $97(46,139)$ & $212(144,318)$ & .002 \\
\hline \multicolumn{4}{|l|}{ Categorized ABG pH } \\
\hline $\mathrm{pH}$ & $7.43(7.32,7.52)$ & $7.38(7.33,7.47)$ & .60 \\
\hline $\mathrm{pH}<7.21, \mathrm{n}(\%)$ & $1(4)$ & 0 & 1.00 \\
\hline Lactate, $\mathrm{mmol} / \mathrm{l}$ & $4(2,6)$ & $3(3,5)$ & .74 \\
\hline Lactate $>5, \mathrm{n}(\%)$ & $7(29)$ & $1(14)$ & .64 \\
\hline \multicolumn{4}{|l|}{ Ventilatory support } \\
\hline Rate, breaths/min & $12(10,22)$ & $10(10,12)$ & .14 \\
\hline PIP, $\mathrm{cm} \mathrm{H} \mathrm{H}_{2} \mathrm{O}$ & $24(22,26)$ & $24(20,26)$ & .53 \\
\hline PEEP, $\mathrm{cm} \mathrm{H}_{2} \mathrm{O}$ & $8(6,10)$ & $5(5,10)$ & .33 \\
\hline Tidal volume, $\mathrm{mL} / \mathrm{kg}$ & $6(5,8)$ & $5(2,7)$ & .09 \\
\hline $\begin{array}{l}\text { Compliance, } \\
\quad \mathrm{mL} \cdot \mathrm{kg}^{-1} \cdot \mathrm{cm} \mathrm{H}_{2} \mathrm{O}^{-1}\end{array}$ & $0.4(0.3,0.5)$ & $0.2(0.1,0.5)$ & .16 \\
\hline Fluid balance, $\mathrm{mL} / \mathrm{kg}$ & $-4(-133,91)$ & $-70(-155,2)$ & .38 \\
\hline Plasma exchange, n (\%) & 0 & 0 & \\
\hline ECMO duration, $\mathrm{h}$ & $32(23,63)$ & $134(25,192)$ & .02 \\
\hline Post-ECMO VF & $1(1,2)$ & $3(2,4)$ & .005 \\
\hline $\begin{array}{l}\text { Post-ECMO epinephrine, } \\
\mu \mathrm{g} \cdot \mathrm{kg}^{-1} \cdot \mathrm{min}^{-1}\end{array}$ & $0.12(0.05,0.11)$ & $0.21(0.20,0.21)$ & .008 \\
\hline $\begin{array}{l}\text { Redo cardiac surgery, } \\
\mathrm{n}(\%)\end{array}$ & 0 & $1(14)^{*}$ & .22 \\
\hline $\begin{array}{l}\text { Invasive interventions, } \\
\mathrm{n}(\%)\end{array}$ & 0 & 0 & \\
\hline
\end{tabular}

ECMO, Extracorporeal membrane oxygenation; $O R-E C M O$, failure to separate from cardiopulmonary bypass in the operating room; $V F$, ventricular function; $A B G$, arterial blood gas; $P I P$, peak inspiratory pressure; $P E E P$, positive end-expiratory pressure. *Tricuspid valve repair in a Norwood patient.

2, ECMO flows at 24 hours, lung compliance, and plasma exchange increased the likelihood of mortality.

The overall incidence of mortality in patients with single ventricle was $50 \%$, in patients with chromosomal/structural abnormalities $59 \%$, and in patients who had plasma exchange $57 \%$.

\section{Other ECMO and Neurologic Outcomes}

Table 7 summarizes the overall ECMO outcomes including short- and long-term neurodevelopmental outcomes. Only $3(3 \%)$ patients required ECMO recannulation. Among the $7(7 \%)$ patients who were transitioned to a VAD, $5(71 \%)$ survived to discharge. Four patients received heart transplantation directly from ECMO, 2 $(50 \%)$ of whom died. One was a neonate with complex heart disease who required ECMO for LCOS. After she received heart transplantation she had a cardiac arrest requiring a second ECMO run. Care was withdrawn owing 
TABLE 4. Pre-ECMO and ECMO variables in the 24 LCOS-ECMO patients

\begin{tabular}{|c|c|c|c|}
\hline & $\begin{array}{c}\text { Survivors } \\
(\mathbf{n}=15)\end{array}$ & $\begin{array}{c}\text { Nonsurvivors } \\
(\mathbf{n}=\mathbf{9})\end{array}$ & $P$ \\
\hline \multicolumn{4}{|l|}{ Pre-ECMO } \\
\hline Pre-ECMO VF & $2(2,3)$ & $3(1,4)$ & .89 \\
\hline \multicolumn{4}{|l|}{ Pre-ECMO therapies } \\
\hline Nitric oxide, n (\%) & $8(53)$ & $3(33)$ & .42 \\
\hline HFOV, n $(\%)$ & $1(7)$ & $1(11)$ & 1.00 \\
\hline \multicolumn{4}{|l|}{ Categorized $\mathrm{ABG} \mathrm{pH}$} \\
\hline $\mathrm{pH}$ & $7.36(7.26,7.45)$ & $7.35(7.26,7.42)$ & 1.00 \\
\hline $\mathrm{pH}<7.21, \mathrm{n}(\%)$ & $1(7)$ & $1(11)$ & 1.00 \\
\hline Lactate, $\mathrm{mmol} / \mathrm{l}$ & $5(2,10)$ & $8(5,11)$ & .23 \\
\hline Lactate $>5, \mathrm{n}(\%)$ & $7(47)$ & $6(67)$ & .42 \\
\hline $\begin{array}{l}\text { Epinephrine, } \\
\quad \mu \mathrm{g} \cdot \mathrm{kg}^{-1} \cdot \min ^{-1}\end{array}$ & $0.1(0.05,0.15)$ & $0.13(0.07,0.20)$ & .48 \\
\hline \multicolumn{4}{|l|}{ ECMO } \\
\hline \multicolumn{4}{|l|}{ Cannulation site } \\
\hline Chest, n (\%) & $6(40)$ & $5(56)$ & \\
\hline Neck, n (\%) & $9(60)$ & $4(44)$ & \\
\hline $\begin{array}{l}\text { ECMO flow at } 4 \mathrm{~h}, \\
\mathrm{~mL} \cdot \mathrm{kg}^{-1} \cdot \mathrm{min}^{-1}\end{array}$ & $94(76,155)$ & $147(104,160)$ & .28 \\
\hline $\begin{array}{l}\text { ECMO flow at } 24 \mathrm{~h}, \\
\mathrm{~mL} \cdot \mathrm{kg}^{-1} \cdot \mathrm{min}^{-1}\end{array}$ & $94(59,151)$ & $161(130,185)$ & .0 \\
\hline \multicolumn{4}{|l|}{ Categorized ABG pH } \\
\hline $\mathrm{pH}$ & $7.49(7.28,7.56)$ & $7.52(7.32,7.52)$ & .9 \\
\hline $\mathrm{pH}<7.21, \mathrm{n}(\%)$ & $1(7)$ & 0 & 1.00 \\
\hline Lactate, $\mathrm{mmol} / \mathrm{L}$ & $2(2,4)$ & $4(2,8)$ & .12 \\
\hline Lactate $>5, \mathrm{n}(\%)$ & 0 & $4(44)$ & .01 \\
\hline \multicolumn{4}{|l|}{ Ventilatory support } \\
\hline Rate, breaths/min & $12(10,16)$ & $10(10,13)$ & .62 \\
\hline PIP, $\mathrm{cm} \mathrm{H}_{2} \mathrm{O}$ & $26(18,30)$ & $25(23,26)$ & .63 \\
\hline PEEP, $\mathrm{cm} \mathrm{H}_{2} \mathrm{O}$ & $8(6,10)$ & $10(6,10)$ & .72 \\
\hline Tidal volume, $\mathrm{mL} / \mathrm{kg}$ & $6(2,7)$ & $3(2,5)$ & .35 \\
\hline $\begin{array}{l}\text { Compliance, } \\
\quad \mathrm{mL} \cdot \mathrm{kg}^{-1} \cdot \mathrm{cm} \mathrm{H}_{2} \mathrm{O}^{-1}\end{array}$ & $0.3(0.2,0.5)$ & $0.2(0,0.24)$ & .0 \\
\hline Fluid balance, $\mathrm{mL} / \mathrm{kg}$ & $-20(-106,11)$ & $-20(-17,58)$ & .87 \\
\hline Plasma exchange, $\mathrm{n}(\%)$ & $2(13)$ & $5(56)$ & .06 \\
\hline ECMO duration, $\mathrm{h}$ & $62(32,85)$ & $144(120,237)$ & .20 \\
\hline Post-ECMO VF & $2(1,3)$ & $2(2,4)$ & .60 \\
\hline $\begin{array}{l}\text { Post-ECMO epinephrine, } \\
\mu \mathrm{g} \cdot \mathrm{kg}^{-1} \cdot \mathrm{min}^{-1}\end{array}$ & $0.08(0.05,0.10)$ & $0.05(0.02,0.08)$ & .2 \\
\hline Cardiac surgery, n (\%) & $1(7)^{*}$ & $1(11) \dagger$ & 1.00 \\
\hline $\begin{array}{l}\text { Invasive interventions, } \\
\mathrm{n}(\%)\end{array}$ & $2(13)$ & $3(33)$ & .2 \\
\hline
\end{tabular}

$\overline{E C M O}$, Extracorporeal membrane oxygenation; $L C O S$, low cardiac output syndrome; $V F$, ventricular function; $H F O V$, high frequency oscillatory ventilation; $A B G$, arterial blood gas; PIP, peak inspiratory pressure; PEEP, positive endexpiratory pressure. *Not a redo cardiac surgery: Double-inlet left ventricle double-outlet right ventricle, restrictive ventricular septal defect requiring defect enlargement. $†$ Not a redo cardiac surgery: status post Fontan 2 years prior, now with severe plastic bronchitis, requiring takedown of Fontan and placement of a Blalock-Taussig shunt.

to intracranial bleeding. The second patient was an infant with dilated cardiomyopathy who was placed on ECMO after cardiac arrest. Three weeks after receiving heart transplantation he died of viral septicemia.

At the latest outpatient follow-up, 1.9 years $(0.9,2.9)$ from hospital discharge, 56 patients $(81 \%)$ had normal to mild neurologic disability, and 6 patients $(9 \%)$ died.

\section{DISCUSSION}

Despite increasing utilization and experience with ECMO support in children with cardiac failure, survival for over a decade has remained unchanged and in the order of $38 \%$ to $55 \% .^{1-7}$ The reason for the lack of improved survival is likely multifactorial and among others includes use of ECMO for patients with increasingly more complex cardiac and associated noncardiac defects; ECMO management and complications during ECMO; perhaps delay in initiating ECMO and delay in ECMO decannulation; CPR management; and in patients after cardiac surgery, significant residual cardiac defects. In the current study, however, we were able to demonstrate a considerable in-hospital and intermediate-term survival, reaching $73 \%$ and $66 \%$, respectively. This survival was observed in all of the studied groups, but perhaps of most interest was the survival in the E-CPR group, where shortterm survival was $75 \%$ and long-term survival $70 \%$. This is significantly different from what has recently been demonstrated by some other recent studies in which the reported survival ranged from $34 \%$ to $51 \%$. $^{3,4,10,11}$

\section{Predictors of Mortality}

Given the diversity of cardiac disease, indications for ECMO, and complexity of ECMO variables, different analyses were performed to identify factors that may be associated with mortality. In the multivariable logistic regression models, which included all study patients, indication for ECMO, that is, E-CPR, OR-ECMO, and LCOS-ECMO, did not appear to be independently associated with mortality. Chromosomal anomalies along with having single ventricle and multiple ECMO runs were all significant factors associated with mortality. This increased risk of mortality with chromosomal abnormalities has been shown by others. ${ }^{3}$ The survival in patients with single ventricle was $50 \%$ and, although lower than other patients in our study, it is comparable with what has been reported by Morris ${ }^{1}$ $(37 \%)$ Chan $^{5}(36 \%)$, and their associates. Patients with multiple ECMO runs had a survival of only $29 \%$ and a mortality odds ratio of 15 . This is consistent with other studies in which the survival in patients requiring multiple ECMO runs ranged from $5 \%$ to $38 \%$. ${ }^{1,2}$

In the second model of logistic regression, high ECMO flows at 24 hours, decreased lung compliance, and plasma exchange were all independently associated with increased mortality. Although initial support with higher ECMO flows is required for myocardial recovery and optimal end-organ perfusion, persistent need for higher flows may represent ongoing myocardial dysfunction. In reference to plasma exchange, it is unclear from our data whether the procedure itself contributed to the increased mortality or whether plasma exchange was used more often in the "sickest" of patients. 
TABLE 5. Complications during ECMO

\begin{tabular}{|c|c|c|c|c|c|c|c|c|c|}
\hline & \multicolumn{3}{|c|}{ E-CPR } & \multicolumn{3}{|c|}{ OR-ECMO } & \multicolumn{3}{|c|}{ LCOS-ECMO } \\
\hline & $\mathbf{S}(\mathbf{n}=\mathbf{3 0})$ & NS $(\mathbf{n}=10)$ & $\boldsymbol{P}$ & $S(n=24)$ & NS $(n=7)$ & $\boldsymbol{P}$ & $\mathbf{S}(\mathbf{n}=\mathbf{1 5})$ & $\operatorname{NS}(\mathbf{n}=9)$ & $P$ \\
\hline Any complications, $\mathrm{n}=$ patients $(\%)$ & $14(47)$ & $8(80)$ & .08 & $8(33)$ & $7(100)$ & .002 & $7(47)$ & $9(100)$ & .009 \\
\hline Brain injury & $7(23)$ & $6(60)$ & .052 & $1(4)$ & $3(43)$ & .02 & 0 & $4(44)$ & .01 \\
\hline Seizures, n (\%) & $3(10)$ & 0 & .55 & $1(4)$ & $2(29)$ & .11 & 0 & 0 & \\
\hline CNS bleeding, $\mathrm{n}(\%)$ & $2(7)$ & $4(40)$ & .02 & 0 & $2(29)$ & .04 & 0 & $3(33)$ & .04 \\
\hline CNS infarct, $\mathrm{n}(\%)$ & $2(7)$ & $2(20)$ & .25 & 0 & $1(14)$ & .22 & 0 & $1(11)$ & .37 \\
\hline Renal dysfunction & $6(20)$ & $1(10)$ & .64 & $6(25)$ & $1(14)$ & 1.0 & $4(27)$ & $3(33)$ & 1.00 \\
\hline Bacteremia, n (\%) & $3(10)$ & 0 & .54 & $1(4)$ & $1(14)$ & .40 & 0 & 0 & \\
\hline \multicolumn{10}{|l|}{ ECMO support } \\
\hline Oxygenator failure & $2(7)$ & 0 & 1.0 & $2(8)$ & 0 & 1.0 & 0 & $4(44)$ & .01 \\
\hline Circuit thrombus & $3(10)$ & 0 & .56 & $3(12)$ & 0 & 1.0 & $3(20)$ & $3(33)$ & .63 \\
\hline Cannula, surgical site, other bleeding & $4(13)$ & $1(10)$ & 1.0 & $4(17)$ & $1(14)$ & 1.0 & $2(13)$ & $5(56)$ & 0.06 \\
\hline \multicolumn{10}{|l|}{ Respiratory } \\
\hline Pulmonary hemorrhage & 0 & 0 & & 0 & 0 & & 0 & $2(22)$ & .13 \\
\hline Pneumothorax & 0 & $1(10)$ & .25 & $1(4)$ & 0 & 1.0 & 0 & $1(11)$ & .37 \\
\hline \multicolumn{10}{|l|}{ Cardiac } \\
\hline Arrhythmias & 0 & 0 & & $1(4)$ & 0 & 1.0 & 0 & $1(11)$ & .37 \\
\hline $\mathrm{CPR}$ & 0 & 0 & & 0 & 0 & & 0 & 0 & \\
\hline Inotropes & $3(10)$ & $1(10)$ & 1.0 & $3(12)$ & $1(14)$ & 1.0 & $1(7)$ & $3(33)$ & .13 \\
\hline \multicolumn{10}{|l|}{ Gastrointestinal } \\
\hline Hyperbilirubinemia & $4(13)$ & $1(10)$ & 1.0 & $1(4)$ & 0 & 1.0 & $3(20)$ & $3(33)$ & .63 \\
\hline
\end{tabular}

$\overline{E C M O}$, Extracorporeal membrane oxygenation; $E-C P R$, refractory cardiopulmonary resuscitation; $O R$-ECMO, failure to separate from cardiopulmonary bypass in the operating room; $L C O S$, low cardiac output syndrome; $S$, survivors; $N S$, nonsurvivors; $C N S$, central nervous system; $C P R$, cardiopulmonary resuscitation

\section{E-CPR}

The E-CPR group had a $75 \%$ survival to hospital discharge. The most important factors associated with decreased survival were cardiac arrest in patients with single ventricle, younger age, higher epinephrine dose before

TABLE 6. Multivariable logistic regression models showing predictors of mortality

\begin{tabular}{lrcl}
\hline & OR & $\mathbf{9 5} \%$ CI & $\boldsymbol{P}$ \\
\hline Model 1: Baseline and pre-ECMO factors* & & & \\
Weight & 0.8 & & .36 \\
Cardiac diagnosis $(\mathrm{SV}) \dagger$ & 5.9 & $3.2-33.1$ & .02 \\
Chromosomal/structural abnormalities & 8.3 & $2.5-35.0$ & .005 \\
Pre-ECMO therapies $\ddagger$ & 1.4 & & .60 \\
Epinephrine dose $>0.2 \mu \mathrm{g} \cdot \mathrm{kg}^{-1} \cdot \mathrm{min}^{-1}$ & 2.1 & & .14 \\
Multiple ECMO runs & 15.3 & $4.5-42.3$ & $<.001$ \\
Model 2: ECMO factors $§$ & & & \\
ECMO flow at $24 \mathrm{~h}>185 \mathrm{~mL} \cdot \mathrm{kg}^{-1} \cdot \mathrm{min}^{-1}$ & 8.4 & $4.0-21.8$ & .005 \\
pH $<7.21$ & 0.8 & & .37 \\
Lactate $>5$ & 3.2 & & .09 \\
Lung compliance $<0.21 \mathrm{~mL} \cdot \mathrm{kg}^{-} \mathrm{cm}^{-1} \mathrm{H}_{2} \mathrm{O}^{-1}$ & 5.2 & $2.5-16.1$ & .02 \\
Creatinine $>1.2 \mathrm{mg} / \mathrm{dL}$ & 2.0 & & .14 \\
CNS infarct & 0.1 & & .78 \\
CNS hemorrhage & 1.5 & & .23 \\
Plasma exchange & 5.1 & $3.4-18.0$ & .03 \\
ECMO duration $>180 \mathrm{~h}$ & 0.2 & & .66 \\
\hline
\end{tabular}

In all ECMO patients, parameters were adjusted for multicollinearity. $O R$, Odds ratio; $C I$, confidence interval; $E C M O$, extracorporeal membrane oxygenation; $S V$, single ventricle; $C N S$, central nervous system. $*$ Model 1 characteristics: $\mathrm{n}=91$; HosmerLemeshow $P=.82$. $†$ Two-ventricle versus single ventricle. Primary myocardial disease and pulmonary hypertension were classified as a 2-ventricle parameter to run the regression analysis. ఫHigh frequency oscillation and nitric oxide. §Model 2 characteristics: $\mathrm{n}=93$; Hosmer-Lemeshow $P=0.91$. arrest, significant metabolic acidosis during the early ECMO course, and development of intracranial hemorrhage. The duration of CPR did not differ between survivors and nonsurvivors, as other studies have shown, ${ }^{3,10}$ but contrary to other reports, ECMO duration did not differ either. In patients with single ventricle, E-CPR had a survival of only $36 \%$, which is comparable with recent reported Extracorporeal Life Support Organization outcomes. ${ }^{5}$

In an attempt to identify factors that could be contributing to the increased E-CPR survival in the current study, we compared our results with the findings from 2 other notable ECPR studies. The first study was by Kane and associates, ${ }^{3}$ who reported their institutional findings in 172 patients from 1995 to 2008 and had a survival of $51 \%$; the second was by Chan and colleagues, ${ }^{5}$ who reported the Extracorporeal Life Support Organization E-CPR outcomes in 492 patients from 1992 to 2005 and had a survival of $42 \%$. Overall, it appears that in the current study, there were significantly fewer complications, for example, bleeding, sepsis, and renal insufficiency, less acidosis, improved, higher initial ECMO flows, and significantly decreased ECMO duration. We can only speculate whether these differences are true and how they influence survival. Some of the complications, such as central nervous system infarct and renal failure, are to some extent related to the quality of CPR before ECMO, including minimally interrupted chest compressions during ECMO cannulation, which necessitates a technically skilled cannulation team. Beyond this, however, we strongly believe in delivering higher initial ECMO flows and thus improved cardiac 
TABLE 7. Short- and intermediate-term ECMO and neurodevelopmental outcomes

\begin{tabular}{|c|c|c|c|c|}
\hline & $\begin{array}{c}\text { E-CPR } \\
(n=40)\end{array}$ & $\begin{array}{c}\text { OR-ECMO } \\
(\mathbf{n}=\mathbf{3 1})\end{array}$ & $\begin{array}{c}\text { LCOS-ECMO } \\
\quad(n=24)\end{array}$ & $P$ \\
\hline Hospital survival, n (\%) & $30(75.0)$ & $24(77.0)$ & $15(62.5)$ & .40 \\
\hline 28-Day survival, n (\%) & $31(77.5)$ & $26(81.0)$ & $17(71.0)$ & .51 \\
\hline ECMO recovery, n (\%) & $25(62.5)$ & $26(81.0)$ & $15(62.5)$ & .10 \\
\hline ECMO recannulation & $1(2.5)$ & $2(6.0)$ & 0 & .47 \\
\hline ECMO to VAD, n (\%) & $4(10.0)$ & 0 & $3(12.5)$ & .11 \\
\hline $\begin{array}{l}\text { Hospital survival, } \\
\text { n (\%) }\end{array}$ & $4(100)$ & & $1(33)$ & \\
\hline VAD to recovery, $\mathrm{n}$ & 2 & & 1 & \\
\hline VAD to transplant, $\mathrm{n}$ & 2 & & & \\
\hline $\begin{array}{l}\text { ECMO to transplant, } \\
\text { n (\%) }\end{array}$ & $2(5)$ & 0 & $2(8)$ & .28 \\
\hline $\begin{array}{l}\text { Hospital survival, } \\
\text { n, }(\%)\end{array}$ & $1(50)$ & & $1(50)$ & \\
\hline $\begin{array}{l}\text { Multiple ECMO runs, } \\
\text { n (\%) }\end{array}$ & $2(5)$ & $3(10)$ & $2(8)$ & .69 \\
\hline 2-runs, n & $2^{*}$ & $2 \dagger$ & $2 \ddagger$ & \\
\hline 3-runs, n & & $1 \S$ & & \\
\hline \multicolumn{5}{|l|}{$\begin{array}{l}\text { Neurodevelopmental } \\
\text { outcomes }\end{array}$} \\
\hline \multicolumn{5}{|l|}{$\begin{array}{l}\text { POPC scale at latest } \\
\text { follow-up }\end{array}$} \\
\hline $\begin{array}{l}\text { Interval time from } \\
\text { ECMO, y }\end{array}$ & $1.7(1,4)$ & $2(1,3)$ & $1.7(0.6,3)$ & .63 \\
\hline Survival, n (\%) & $28(70)$ & $22(71)$ & $13(54)$ & .30 \\
\hline $\begin{array}{l}\text { Good-mild } \\
\quad \text { disability, } \mathrm{n}(\%)\end{array}$ & $24(80)$ & $20(83)$ & $12(80)$ & 1.00 \\
\hline $\begin{array}{l}\text { Moderate-severe } \\
\text { disability, } \mathrm{n}(\%)\end{array}$ & $4(13)$ & $2(8)$ & $1(7)$ & .77 \\
\hline Death, n $(\%)$ & $2(7)$ & $2(8)$ & $2(13)$ & .75 \\
\hline
\end{tabular}

$E C M O$, Extracorporeal membrane oxygenation; $E-C P R$, refractory cardiopulmonary resuscitation; $O R-E C M O$, failure to separate from cardiopulmonary bypass in the operating room; $L C O S$, low cardiac output syndrome; $V A D$, ventricular assist device; $P O P C$, Pediatric Overall Performance Category scale. *One patient survived and 1 died. $\dagger$ Both died. $\ddagger$ Both patients died. One died after being transitioned to VAD and the other after a heart transplant. §Survived.

output, particularly after cardiac arrest when end organs including the myocardium have likely had a degree of hypoxic injury. Last and perhaps equally important, we speculate that the shorter ECMO duration plays a role in this. As outlined in our Methods section, another strategy used in our cardiac intensive care unit that may be associated with these improved outcomes is the early and frequent assessment for readiness for ECMO decannulation. This approach is perhaps used by other centers as well, and possibly it represents a change in the "philosophy" of ECMO and need for ECMO. Though a life-saving procedure, ECMO carries an abundance of risks, and we make every attempt to transition patients off ECMO, even at the expense of inotropic support.

\section{OR-ECMO}

The highest survival to hospital discharge, $77 \%$, was noted in the OR-ECMO group. Some of the relevant factors associated with mortality included lower weight and a constellation of parameters that are probably linked to each other. These included higher ECMO flows at 4 and 24 hours and decreased ventricular function and increased inotropic support after decannulation. In addition, nonsurvivors had longer ECMO duration and significantly more complications including intracranial hemorrhage. Inasmuch as this was a surgical group, we also looked at the incidence of residual cardiac defects and found only $1(3 \%)$ patient who required surgical reintervention.

Published single-center reports show that the overall hospital survival for patients who fail to separate from CPB is around $47 \%$ with a range from $35 \%$ to $61 \%$. ${ }^{1,6,11-18}$

Beyond some of the risk factors already mentioned under the E-CPR section, the presence of hemodynamically significant residual cardiac defects is associated with poor survival. ${ }^{1,11,15,19}$ In the recent study by Alsoufi and coworkers, ${ }^{11} 37 \%$ of the patients required ECMO for failure to separate from $\mathrm{CPB}$ and, among these, $20 \%$ required redo cardiac surgery with only $24 \%$ surviving to hospital discharge. In another study by Morris and coworkers, ${ }^{1}$ which included 13 patients for failure to separate from CPB, $54 \%$ required redo cardiac surgery. In general, significant residual cardiac lesions are poorly tolerated after cardiac surgery and thus weaning from ECMO may not be possible.

Another explanation, however, for the higher survival in this study is the possibility of lower threshold for placing patients on ECMO. Inasmuch as we do not have the exact intraoperative data, it is conceivable that perhaps a "slower" wean from CPB with more inotropic agents might have avoided the use of ECMO.

\section{LCOS-ECMO}

The lowest survival, $62.5 \%$, was noted in the LCOSECMO group. Nonsurvivors in this group had significantly more chromosomal and noncardiac defects, increased ECMO flow requirement at 24 hours, increased lactic acidosis, and, as with previous groups, more complications including intracranial bleeding, ECMO circuit thrombi, and oxygenator failure. It is unclear why this group appeared to have had more circuit thrombi and oxygenator failures, but perhaps this is related to anticoagulation inconsistencies. However, inasmuch as we did not collect data on anticoagulation, we cannot be certain. Anecdotally, though, after our program converted to Quadrox oxygenators we witnessed fewer failures. The lower survival in this group was rather surprising, particularly when the main objective of deploying ECMO in these patients was to prevent possible cardiac arrest and therefore improve survival. Compared with the other 2 groups, it appeared that these patients had a tendency toward longer ECMO course and had higher 24-hour ECMO flows. These factors perhaps indicate an underlying significant myocardial dysfunction that precluded ECMO decannulation. In addition, however, this group seemed to have 
had more ECMO circuit-related complications, more pulmonary complications, lower lung compliance, and more hemolysis. It is difficult to conclude whether all these events were secondary to possible ongoing myocardial dysfunction and longer ECMO course or whether they occurred owing to "prolonged" LCOS and perhaps earlier ECMO deployment would have prevented them. It is also possible that merely having more patients with chromosomal and other noncardiac structural defects predisposed this group to more complications and higher mortality.

\section{Complications}

Despite our aggressive laboratory and imaging monitoring, we still witnessed a fair number of complications that, to an extent, appear to be associated with our mortality. Although we are constantly reevaluating and improving our ECMO management protocol, it is not realistic to expect no complications in such a nonphysiologic circulation. Therefore, a strong effort should always be made to shorten ECMO duration when possible.

\section{Neurodevelopmental Outcomes}

Neurologic injury after ECMO and particularly after E-CPR is one of the most concerning and well-documented complications. ${ }^{20}$ The incidence, however, varies among institutions. This is partly because of how neurologic injury is defined from study to study, which can include acute clinical symptoms, functional outcomes, or any radiologic evidence. In our study, the overall incidence of acute neurologic injury was $22 \%$, which is comparable with the incidence reported by Barrett and colleagues ${ }^{21}$ in E-CPR patients. From a neurodevelopmental standpoint, in the intermediate-term, $89 \%$ of the survivors had either normal assessment or only mild disability. Although the POPC scale used in this study is limited because it lacks detailed assessment of intelligence and cognitive function, this scale has been shown to predict performance in the more meticulous psychometric testing. ${ }^{9}$ Nevertheless, standardized comprehensive neuropsychologic testing is of paramount importance in all these patients and we are currently in the process of evaluating all survivors.

\section{CONCLUSIONS}

ECMO was successfully used in children with cardiac disease, with $73 \%$ and $66 \%$ short- and intermediate-term survival, respectively, with the majority of the survivors having normal or only minimal neurodevelopmental deficit. A sustained, interdisciplinary team of cardiothoracic surgeons, cardiac intensivists, and perfusionists that is able to adopt and continuously improve on the peri-ECMO management approach with strict protocols is vital to this success.

\footnotetext{
References

1. Morris MC, Ittenbach RF, Godinez RI, Portnoy JD, Tabbutt S, Hanna BD, et al. Risk factors for mortality in 137 pediatric cardiac intensive care unit patients
}

managed with extracorporeal membrane oxygenation. Crit Care Med. 2004; 32:1061-9.

2. Alsoufi B, Al-Radi OO, Gruenwald C, Lean L, Williams WG, McCrindle BW, et al. Extra-corporeal life support following cardiac surgery in children: analysis of risk factors and survival in a single institution. Eur J Cardiothorac Surg. 2009; 35:1004-11.

3. Kane DA, Thiagarajan RR, Wypij D, Scheurer MA, Fynn-Thompson F, Emani S, et al. Rapid-response extracorporeal membrane oxygenation to support cardiopulmonary resuscitation in children with cardiac disease. Circulation. 2010; 122(11 Suppl):S241-8.

4. Thiagarajan RR, Laussen PC, Rycus PT, Bartlett RH, Bratton SL. Extracorporeal membrane oxygenation to aid cardiopulmonary resuscitation in infants and children. Circulation. 2007;116:1693-700.

5. Chan T, Thiagarajan RR, Frank D, Bratton SL. Survival after extracorporeal cardiopulmonary resuscitation in infants and children with heart disease. $J$ Thorac Cardiovasc Surg. 2008;136:984-92.

6. Delmo Walter EM, Alexi-Meskishvili V, Huebler M, Loforte A, Stiller B, Weng Y, et al. Extracorporeal membrane oxygenation for intraoperative cardiac support in children with congenital heart disease. Interact Cardiovasc Thorac Surg. 2010;10:753-8.

7. Hannan RL, Ojito JW, Ybarra MA, O'Brien MC, Rossi AF, Burke RP. Rapid cardiopulmonary support in children with heart disease: a nine-year experience. Ann Thorac Surg. 2006;82:1637-41.

8. Jacobs JP, Lacour-Gayet FG, Jacobs ML, Clarke DR, Tchervenkov CI, Gaynor JW, et al. Initial application in the STS congenital database of complexity adjustment to evaluate surgical case mix and results. Ann Thorac Surg. 2005;79:1635-49.

9. Fiser DH, Long N, Roberson PK, Hefley G, Zolten K, Brodie-Fowler M. Relationship of pediatric overall performance category and pediatric cerebral performance category scores at pediatric intensive care unit discharge with outcome measures collected at hospital discharge and 1- and 6-month follow-up assessments. Crit Care Med. 2000;28:2616-20.

10. Raymond TT, Cunnyngham CB, Thompson MT, Thomas JA, Dalton HJ Nadkarni VM. American Heart Association National Registry of CPR Investigators. Outcomes among neonates, infants, and children after extracorporeal cardiopulmonary resuscitation for refractory inhospital pediatric cardiac arrest: a report from the National Registry of Cardiopulmonary Resuscitation. Pediatr Crit Care Med. 2010;11:362-71.

11. Alsoufi B, Al-Radi OO, Nazer RI, Gruenwald C, Foreman C, Williams WG, et al Survival outcomes after rescue extracorporeal cardiopulmonary resuscitation in pediatric patients with refractory cardiac arrest. J Thorac Cardiovasc Surg. 2007; 134:952-9.

12. Walters HL 3rd, Hakimi M, Rice MD, Lyons JM, Whittlesey GC, Klein MD. Pediatric cardiac surgical ECMO: multivariate analysis of risk factors for hospital death. Ann Thorac Surg. 1995;60:329-36.

13. Jaggers JJ, Forbess JM, Shah AS, Meliones JN, Kirshbom PM, Miller CE, et al Extracorporeal membrane oxygenation for infant postcardiotomy support: significance of shunt management. Ann Thorac Surg. 2000;69:1476-83.

14. Aharon AS, Drinkwater DC Jr, Churchwell KB, Quisling SV, Reddy VS, Taylor M, et al. Extracorporeal membrane oxygenation in children after repair of congenital cardiac lesions. Ann Thorac Surg. 2001;72:2095-101.

15. Kolovos NS, Bratton SL, Moler FW, Bove EL, Ohye RG, Bartlett RH, et al. Outcome of pediatric patients treated with extracorporeal life support after cardiac surgery. Ann Thorac Surg. 2003;76:1435-41.

16. Chaturvedi RR, Macrae D, Brown KL, Schindler M, Smith EC, Davis KB, et al. Cardiac ECMO for biventricular hearts after paediatric open heart surgery. Heart. 2004; $90: 545-51$

17. Alsoufi B, Shen I, Karamlou T, Giacomuzzi C, Burch G, Silberbach M, et al. Extracorporeal life support in neonates, infants, and children after repair of congenital heart disease: modern era results in a single institution. Ann Thorac Surg. 2005;80:15-21.

18. Thourani VH, Kirshbom PM, Kanter KR, Simsic J, Kogon BE, Wagoner S, et al Venoarterial extracorporeal membrane oxygenation (VA-ECMO) in pediatric cardiac support. Ann Thorac Surg. 2006;82:138-44.

19. Black MD, Coles JG, Williams WG, Rebeyka IM, Trusler GA, Bohn D, et al. Determinants of success in pediatric cardiac patients undergoing extracorporeal membrane oxygenation. Ann Thorac Surg. 1995;60:133-8.

20. Cengiz P, Seidel K, Rycus PT, Brogan TV, Roberts JS. Central nervous system complications during pediatric extracorporeal life support; incidence and risk factors. Crit Care Med. 2005;33:2817-24.

21. Barrett CS, Bratton SL, Salvin JW, Laussen PC, Rycus PT, Thiagarajan RR. Neurological injury after extracorporeal membrane oxygenation use to aid pediatric cardiopulmonary resuscitation. Pediatr Crit Care Med. 2009;10:445-51. 